\title{
Comparative Study of the Perception of the Role of a Social Worker in Hospitals in the Czech Republic and Slovakia during the COVID-19 Pandemic
}

\section{P. Laca (Peter Laca)1', S. Laca (Slavomir Laca) ${ }^{2}$}

${ }^{1}$ University of Health and Social Work of St. Elisabeth Bratislava, SK.

${ }^{2}$ Prague University of Psychosocial Studies, Prague, CZ.

\section{E-mail address:}

peter.laca16@gmail.com

\section{Reprint address:}

Peter Laca

University of Health and Social Work of St. Elizabeth

Kos Schoppera 22

04801 Roznava

Slovakia

Source: Clinical Social Work and Health Intervention

Pages: $23-30$

Volume: 12

Issue: 4

\section{Reviewers:}

Selvaraj Subramaniam

Kuala Lumpur

Vitalis Okoth Odero

Catholic university of Eastern Africa, Nairobi, Kenya

Cited references: 8

\section{Keywords:}

COVID 19. Epidemic. Nurse. Social Worker. Research.

\section{Publisher:}

International Society of Applied Preventive Medicine i-gap

CSWHI 2021; 12(4): 23 - 30; DOI: 10.22359/cswhi_12_4_03 CC Clinical Social Work and Health Intervention

\section{Abstract:}

This research study is focused on the perception of the role of a social worker by hospital nurses in the Czech and Slovak Republic during the COVID-19 pandemic.

Aim of the study: The main aim of the research study was to find the opinions of nurses from the Czech and Slovak Republic on a social worker who works in a hospital during a coronavirus - COVID-19 pandemic and then compare their opinions in helping patients

Research sample and setting: The research sample of the study consisted of 75 nurses with higher professional education (Czech Republic), university education of the first and second degree (Czech Republic, Slovak Republic), who were together with social workers in the front line in hospitals at the time of 
the coronavirus pandemic COVID-19. All participating respondents were informed about the purpose of the research study and the completion of the online questionnaire.

Statistical analysis: The mathematical-statistical method chisquare test of the independence of the criteria of individual research hypotheses was used to compare the interviewed respondents in the Czech Republic and Slovakia.

Results of the study: Medical staff at the time of the COVID19 pandemic was satisfied with the social worker, as evidenced by the research study and their answers in the questionnaire survey. It is clear from the results of the research survey that the participants perceived the social worker positively during the COVID-19 pandemic.

\section{Introduction}

The pandemic of the SARS-CoV-2 virus, simply referred to as Covid-19, complicated the lives of perhaps every social group of various professions, including social workers and medical staff in hospitals in every country, with no exception of the Czech and Slovak Republic.

The role of every healthcare facility in the Czech or Slovak Republic, especially hospitals, is to provide healthcare, and during a pandemic, it is acute healthcare. Each pandemic will reflect the readiness and cooperation of the individual components - within the staff who work in the hospital. If the hospital does not have enough medical staff, especially during the Covid-19 pandemic, covid patients and healthcare professionals are assisted by people from related professions, e.g. from the Department of Social Work, specifically social workers in healthcare.

Social Work in healthcare is a specialized activity in the field of Social Work. It can be perceived as a professional provision of social services focused primarily on helping clients, their families and the community in which clients are located. Further, it improves or maintains proper functioning in relation to their own health (Hrozenska, Drzsíková, 2016), which can be seen in the practical activities of the Covid-19 pandemic. According to Kuzniková (2011, p. 18), the role of social work in healthcare is "using the influence of the psychosocial sphere on the disease to adapt better, to overcome difficulties, to motivate for treatment and cooperation, and finally to improve the quality of life." Therefore, it is necessary to use complex care for the client, i.e. the patient.
The Covid-19 pandemic culminated in the Czech Republic around 12 April 2020, when a total of 4,800 people with Covid-19 were registered, of which 436 were hospitalized, including hundreds of patients who were in serious condition. The number of infected and sick began to increase again during the summer of 2020, a significant outbreak of the disease (per capita) was the capital city of Prague in large numbers visited by foreign tourists. In the following months, the incidence of the disease spread to almost the entire republic. However, in contrast to the spring culmination, there was no similar increase in hospitalizations; the spread of the disease among the younger population in the Czech Republic contributed to this. The culmination of the whole situation was in September 2020, when the Czech Republic ranked among the most affected countries in Europe in terms of the number of newly infected per million inhabitants (Central, 2020). Individual data of the Czech Republic within September 2020 were unfavorable, the number of newly detected cases exceeded 1,000 persons for the first time and the daily increase was greater than 2,000 persons. The whole situation eased in the summer months. At the beginning of 2021, however, the Covid-19 pandemic returned in the form of a second wave.

According to the Ministry of Health of the Czech Republic, there are officially 30,363 deaths (victims) in Covid-19 in the Czech Republic in July 2021.

As part of the culmination of the Covid-19 coronavirus pandemic, not only the number of hospitalized patients in the Czech Republic grew in the Czech Republic, but also the number of people in severe condition requiring intensive 
care grew. The Ministry of Health of the Czech Republic gradually published new data, from which it was possible to read the current numbers of hospitalized, bed capacity, available hospital staff and support staff, including many social workers.

The development of the Covid-19 pandemic in Slovakia was initially milder than in comparison with the Czech Republic, as evidenced by individual statistics and measures adopted by the Slovak government. The first case was confirmed in Slovakia in March 2020, on the basis of which measures were taken by the Ministry of Health and the Central Crisis Staff against the epidemic, an emergency situation was declared, schools were closed, and an emergency situation began to apply. Since March 2020, the number of people positive for Covid-19 has grown by dozens of people in each self-governing region. On 15 March, the Government of the Slovak Republic declared a state of emergency for state hospitals in Slovakia, which was extended to other medical facilities and social service homes. In April, the number of infected and the number of victims rose. At the end of May, Slovakia had 1,522 cases and 28 victims, another victim was added only after two months on 30 July, and 2,292 cases had already been infected.

In connection with the arrival of the second wave of the pandemic on 1 October, a state of emergency came into force in Slovakia again. At the turn of October and November, area testing took place over three weekends. For the first time on 24 and 25 October in Orava and in the Bardejov district, nationwide testing took place in the whole territory of Slovakia on 31 October and 1 November. Slovakia began to tighten anti-pandemic measures, between 21 October and 13 November the daily increase in new cases exceeded 2,000 . There were not enough beds in the hospitals for patients with COVID-19, the medical staff was exhausted and there was a shortage. Students of medical and health faculties, social workers and volunteers helped.

After a slight improvement in the second half of November, daily case increases began to increase again in December. Between December 18 and January 9, they attacked the 4,000 mark; on the last day of the year there were 6,315 new cases. From December 28, deaths began to exceed 100 per day. The highest number of 204 vic- tims occurred on January 4. In February 2021, Slovakia became the worst in the world in the number of deaths and hospitalized cases per capita. According to the Ministry of Health of the Slovak Republic, there are officially 12,541 deaths (victims) in Covid-19 in Slovakia as of July 2021.

\section{Methodology - Research design}

The issue of social and healthcare is very closely connected (Kuzniková, 2011, p. 19), as evidenced by the practice within individual health and health and social facilities, where social work in healthcare plays a role. According to Kovalčíková (In Mojtová, 2008, p. 18), the goal of social work in healthcare is to provide the necessary support; support; accompaniment; assistance to a client who is in some way disadvantaged due to his health condition.

The research is devoted to the perception of the role of a social worker by nurses in hospitals in the Czech and Slovak Republics during the COVID-19 pandemic. The sample of our comparative study to determine the goal consisted of deliberately selected participants, i.e. nurses who worked with a social worker in the COVID-19 pandemic in the hospital. We deliberately selected this research sample so that we could compare participants by territory, namely the Czech Republic and Slovakia. The author Miovský (2006, p. 135) describes "as a deliberate (sometimes also purposeful) selection of a research sample such a procedure when we purposefully search for participants according to their certain properties. The selection criteria is the currently selected (determined) property (or the manifestation of this property) or the state of belonging to a certain social or other group. This means that, based on a set criteria, we purposefully search for only those individuals who meet this criterion, and at the same time are willing to participate in the research." For the research survey, we chose an online questionnaire research method, which kept the anonymity of our participants. We chose quantitative research because it is designed for humanities research and is suitable for a wide selection of participants.

The aim of the research was to find whether nurses perceive the social worker during the COVID-19 epidemic in hospitals as a benefit, and whether they are satisfied with the coopera- 
tion with the social worker during the provision of assistance to patients during the COVID-19 pandemic in the hospital.

In the analysis and interpretation of the collected data, we first used the mathematical classification of the first degree, then we statistically verified the research hypotheses. Pearson's chisquare test was used to confirm or refute the hypotheses. The chi-square test is one of the statistical methods that allows you to verify that a random variable has certain predetermined probability distributions. This test is the basic and most widely used contingency table independence test, as reported in the study. "The research is based on the idea of comparing the observed frequency and the expected abundance. The contingency table is used in statistics to illustrate and clearly show the relationship between two characters "(Ferjenčík 2000, p. 237). The observed frequencies represent data obtained from participants, the expected frequency is obtained by calculating the following formula:

$$
G=\sum_{i=1}^{r} \sum_{j=1}^{s} \frac{\left(n_{i j}-n_{i j}^{\prime}\right)^{2}}{n_{i j}^{\prime}}
$$

The chi-square test of good agreement is based on the assessment of the difference between the actual (observed) frequencies of occurrence of the values in the sample and the expected frequencies, corresponding to the respective assumed probability distribution. When calculating the $\mathrm{x}^{2}$ test of good agreement, we assume that the null hypothesis holds, and if the calculated value of $x^{2}$ is less than 0.05 , then we reject the null hypothesis because the difference between the observed and expected frequencies was a random factor, Hendl (2004, p. 56).

A questionnaire survey was conducted with nurses in the Czech Republic (Prague) and Slovakia (Košice). A total of 75 people participated in completing the questionnaire. More than 150 respondents were contacted, other respondents rejected us and did not want to participate in research due to workload. The observed characteristics of the respondents were gender and territory, ie the states of the Czech Republic and the Slovak Republic.

From Table 1 it is clear that we divided the participants into two categories, according to the territory (state) and gender to which the research questionnaire was personally given for comple-
Table 1 Number of participants

\begin{tabular}{|c|c|c|c|c|}
\hline \multirow{2}{*}{$\begin{array}{c}\text { Partici- } \\
\text { pants }\end{array}$} & \multicolumn{2}{|c|}{ Czech Republic } & \multicolumn{2}{c|}{ Slovak Republic } \\
\cline { 2 - 5 } & Male & Female & Male & Female \\
\hline Count & 9 & 36 & 3 & 27 \\
\hline \multirow{2}{*}{ Overall } & \multicolumn{2}{|c|}{45} & \multicolumn{2}{|c}{30} \\
\cline { 2 - 5 } & \multicolumn{4}{|c|}{75} \\
\hline
\end{tabular}

tion. Out of the total number of 75 participants (nurses) in the hospital, 36 are women and 9 men from the Czech Republic, and from the Slovak Republic there are 27 women and 3 men.

\section{Results}

\section{Hypothesis 1}

H01 Nurses from the Czech and Slovak Republic perceive the work of a social worker in a hospital during the COVID-19 epidemic as beneficial.

HA1 Nurses from the Czech and Slovak Republics do not perceive the work of a social worker in a hospital during the COVID-19 epidemic as unfavorable.

The result of the research survey shows that out of 75 addressed participants (nurses) from hospitals in the Czech and Slovak Republics, up to 64 consider and perceive a social worker as a benefit in hospitals within the COVID-19 epidemic. In the research, we also encountered the opposite view, where 11 nurses do not perceive a social worker as a benefit in the hospital during the COVID-19 pandemic. These individual responses were subsequently verified by the Chisquare test, which was 0.071 . Based on this result, the alternative hypothesis $\mathrm{H} 1$ was rejected and the null hypothesis H0 was accepted - Nurses from the Czech and Slovak Republic perceive the work of a social worker in a hospital during the COVID-19 epidemic as beneficial.

Based on the calculation of the significance of the Chi-square test, we came to the following conclusions which we present in the previous contingency table and Graph 1 . It can be stated that the observed frequency showed that out of the total number of 75 participants, 64 percieve the presence of a social worker at hospitals at the time of the COVID-19 epidemic as a benefit. The opposite opinion had 11 nurses who do not perceive the social worker as a benefit in the hospital at the time of COVID-19. In the subsequent cal- 
Contingency Table 1 of the Chi-square test calculation

\begin{tabular}{|c|c|c|c|c|c|}
\hline \multicolumn{2}{|c|}{ Expected frequency } & Beneficial & Unfavourable & \multirow{2}{*}{\multicolumn{2}{|c|}{ Overall }} \\
\hline \multirow{2}{*}{ Nurses } & Czech Republic & 38,04 & 6,6 & & \\
\hline & Slovak Republic & 25,06 & 4,4 & \multicolumn{2}{|c|}{ n.j 30} \\
\hline \multirow{2}{*}{\multicolumn{2}{|c|}{ Total sum }} & $n_{1} 64$ & $\mathrm{n}_{2} 11$ & \multicolumn{2}{|c|}{ n.j 75} \\
\hline & & $\begin{array}{l}\text { Significance } \\
\text { level }\end{array}$ & $\alpha 5 \%$ & \begin{tabular}{c|} 
Chi-square \\
test indication
\end{tabular} & G 0,071 \\
\hline \multicolumn{4}{|c|}{$\begin{array}{l}\text { After substituting into the formula, the test criterion is } \\
\text { based: } G 0,071\end{array}$} & \multicolumn{2}{|c|}{ Evaluation: } \\
\hline \multicolumn{4}{|c|}{ 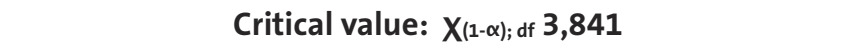 } & $X(1-\alpha) ;$ df $3, \varepsilon$ & $L>0,071$ \\
\hline \multicolumn{6}{|c|}{$\begin{array}{l}\text { At the level of significance of } 5 \% \text {, the null hypothesis } \mathrm{H} 01 \text { of nurses from the Czech and } \\
\text { Slovak Republics perceive the work of a social worker in a hospital during the COVID-19 } \\
\text { epidemic as beneficial, about the independence of individual features, because the value } \\
\text { of the tested criterion is less than the critical value. }\end{array}$} \\
\hline
\end{tabular}

Contingency Graph 1 of the calculation of the significance of the Chi-square test for hypothesis 1

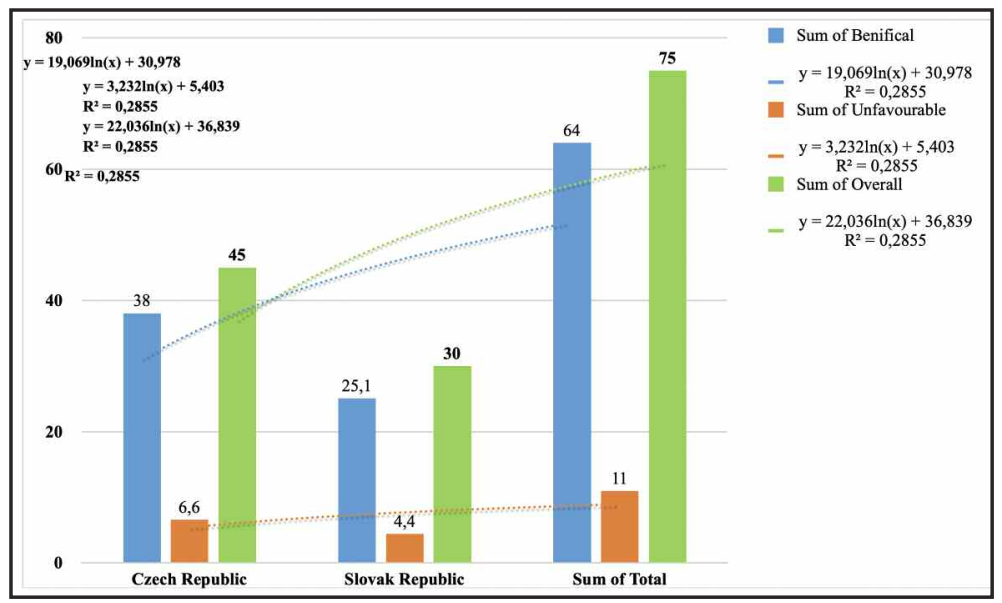

culation of the chi - square, its result was set at 0.071 . The significance value of 0.071 is less than the critical 3.841. The graph also showed the logarithmic sum and the logarithmic curve based on a five-step calculation - of the total sum of the participants' responses, in our case the nurses who worked with a social worker during the COVID-19 epidemic in the hospital.

\section{Hypothesis 2}

H02 Nurses from the Czech and Slovak Republic are satisfied with the cooperation of a so- cial worker in a hospital during the COVID-19 epidemic.

HA2 Nurses from the Czech and Slovak Republics are not satisfied with the cooperation of a social worker in a hospital during the COVID19 epidemic.

The result of the research investigation shows that out of 75 addressed participants (nurses) from hospitals in the Czech and Slovak Republics, up to 63 are satisfied with the cooperation of a social worker during the COVID-19 epidemic. 12 participants were of the opposite opin- 
Contingency Table 2 of the Chi-square test calculation

\begin{tabular}{|c|c|c|c|c|c|}
\hline \multicolumn{2}{|c|}{ Expected frequency } & Satisfied & Dissatisfied & \multirow{2}{*}{\multicolumn{2}{|c|}{$\begin{array}{c}\text { Overall } \\
n_{\cdot j} 45\end{array}$}} \\
\hline \multirow{2}{*}{ Nurses } & Czech Republic & 37,8 & 7,2 & & \\
\hline & Slovak Republic & 25,2 & 4,8 & \multicolumn{2}{|c|}{$n_{. j} 30$} \\
\hline \multirow{2}{*}{\multicolumn{2}{|c|}{ Total sum }} & $n_{1} 63$ & $\mathrm{n}_{2} 12$ & \multicolumn{2}{|c|}{ n.j 75} \\
\hline & & $\begin{array}{c}\text { Significance } \\
\text { level }\end{array}$ & $\alpha 5 \%$ & $\begin{array}{c}\text { Chi-square } \\
\text { test indication }\end{array}$ & G 0,017 \\
\hline \multicolumn{4}{|c|}{$\begin{array}{l}\text { After substituting into the formula, the test criterion is } \\
\text { based: } \mathrm{G} 0,017\end{array}$} & \multicolumn{2}{|c|}{ Evaluation: } \\
\hline \multicolumn{4}{|c|}{ 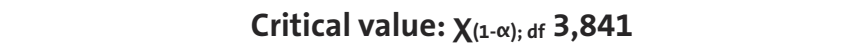 } & $X(1-\alpha)$; df 3 , & $>0,017$ \\
\hline \multicolumn{6}{|c|}{$\begin{array}{l}\text { At the significance level of } 5 \% \text { null hypothesis } \mathrm{H} 02 \text { Nurses from the Czech and Slovak Republic } \\
\text { are satisfied with the cooperation of a social worker during the COVID-19 epidemic in the hos- } \\
\text { pital, about the independence of individual features, because the value of the tested criterion } \\
\text { is less than the critical value. }\end{array}$} \\
\hline
\end{tabular}

Contingency Graph 2 of the calculation of the significance of the Chi-square test for Hypothesis 2

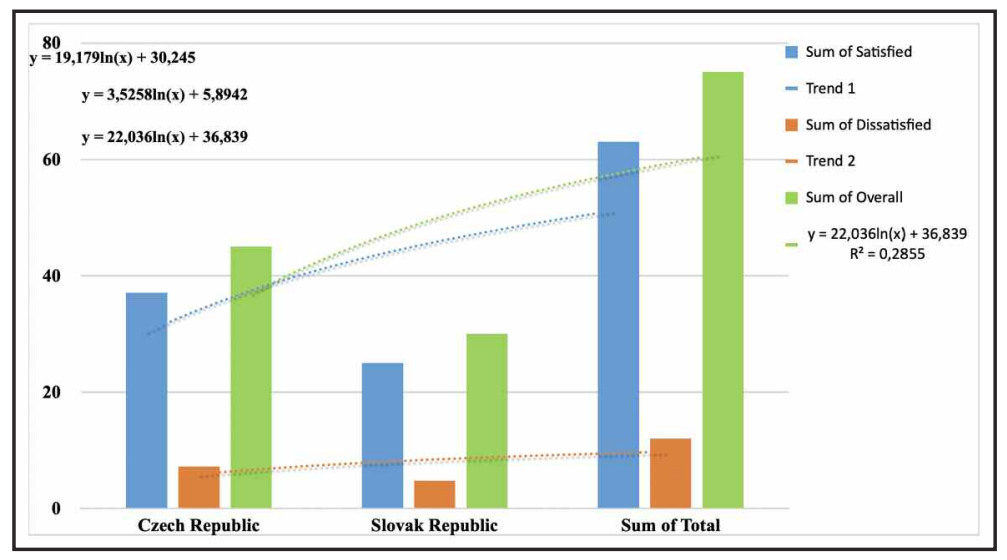

ion, i.e. they were not satisfied with the cooperation during the COVID-19 pandemic. Subsequently, we verified the individual answers with a Chi-square test, which turned out to be 0.017 . Based on this result, the alternative hypothesis $\mathrm{H} 2$ was rejected and the null hypothesis $\mathrm{H} 02$ was accepted - Nurses from the Czech and Slovak Republics are satisfied with the cooperation of a social worker in a hospital during the COVID-19 epidemic.

Based on the calculation of the significance of the Chi-square test, we came to the following conclusions, which we present in the previous contingency table and graph 2 . It can be stated that the observed frequency showed that a total of 75 participants were 63 nurses satisfied in the COVID-19 epidemic. 12 sisters were of the opposite opinion, i.e. not satisfied. In the subsequent calculation of the chi - square, its result was set at 0.017 . The significance value of 0.017 is less than the critical value of 3.841 . The graph also showed the logarithmic sum and the logarithmic curve - based on the calculation of five degrees - from the total sum of the answers of the participants, in our case the nurses. 


\section{Conclusions of Research Results}

The aim of this research study was to find the opinions of nurses from the Czech and Slovak Republics on a social worker presence and then compare their opinions in helping patients in the hospital during the corona of the COVID-19 viral pandemic. To fulfill this aim, we set two secondary research aims and defined two hypotheses, the null and the alternative hypothesis. Within the methodology of the selected quantitative research survey, a research sample of nurses was presented, namely a total of 75 patients, the questionnaire method of data collection and statistical evaluation of these collected data was verified by a good agreement test, chi-square test, where we could rule out one of the hypotheses. and thus confirm the second hypothesis.

The first side research aim was to determine whether there is a significant difference between nurses in the Czech and Slovak Republics in the area of perception of the contribution of a social worker in a hospital during the COVID-19 epidemic. Based on the answers of the participants verified by the chi-square test, the null hypothesis was accepted - H01 Nurses from the Czech and Slovak Republics perceive the work of a social worker in a hospital as beneficial during the COVID-19 epidemic.

The result therefore shows that nurses in the Czech and Slovak Republics perceive the work of a social worker in a hospital during the COVID-19 epidemic as beneficial. The results of the survey are relevant because a small sample of only 75 participants from two hospitals was found, in Prague and Košice. It would be necessary to compare these data in all hospitals in the Czech Republic and Slovakia, where social workers work. Social workers in healthcare have: complex professional and professional (theoretical-practical) knowledge; participation in satisfying not only the social needs of the client; the ability of independent highly professional work as stated by the author Laca (2016). Professors of social work Mačkinová and Kopinec (2019) point to the general competencies of social work in healthcare as a "functional manifestation of good management and recognition of the professional role of a social worker which includes expertise and ability to reflect adequate context and sensitively apply professional values."

The second aim was to find, in case of satis- faction or dissatisfaction, cooperation of a social worker with nurses in hospitals. Based on the answers of the participants verified by the chisquare test, the null hypothesis H20 was accepted. Nurses from the Czech and Slovak Republic are satisfied with the cooperation of a social worker in the hospital during the COVID-19 epidemic.

The results show that out of 75 participants, 63 were satisfied in cooperation with a social worker. Even in this case, we consider the result to be relevant, because it also confirms the result of the survey where individual participants (nurses) from the Czech and Slovak Republics expressed disagreement, but the verification of individual data showed us the confirmation of the null hypothesis.

As we can see from this research study, the role of a social worker in the hospital is well perceived in both countries, in the Czech and in Slovakia Republics. A health and social worker is basically a social worker working in a healthcare facility who knows both social and health issues. This combination of knowledge is essential for social work in health care facilities. To set up good patient care, the healthcare professional needs to understand the patient's illness. The link between health and social care is constantly evolving, and as we can see is particularly needed in the current COVID-19 pandemic.

\section{Conclusion}

When a new coronavirus pandemic spread during 2020, various measures began to be taken in all countries to mitigate its spread and consequences. One of these measures was the restriction of outings and social contacts, which most significantly affected working and especially school life, as school teaching in the school year 2020/2021 was interrupted in the Czech Republic and Slovakia and was not resumed by the end of the calendar year 2020. It was renewed only for kindergartens, the first stage of primary schools and the last years of secondary schools, which could return to schools on the basis of the COVID vending machine.

The presented research study deals with the perception of a social worker by nurses in hospitals in the Czech and Slovakia Republics during the COVID-19 pandemic. The entire issue of the corona wave of the COVID-19 viral epidemic 
has affected the whole of human society in every area. Society's response to the pandemic has resulted in health, social and economic disruption. This has led to: the postponement or cancellation of several cultural, social and sporting events; a widespread hortage of supplies of medical supplies; exacerbated panic fears in society.

The above results show that the participants (nurses) in hospitals at the time of the corona wave COVID-19 were satisfied with the social worker. We can say that the Covid-19 pandemic has so far affected the functioning of various professions, not excluding social work and social workers around the world. The pandemic we have been facing for the last year is increasingly uniting our society not only professionally but also humanly. It is therefore necessary for people to be aware of the meritorious and professional work that a multidisciplinary team will do and it is not only in hospitals. However, we must not forget the friendly gestures, understanding and mutual help that is needed to overcome COVID19 in our society.

\section{References}

1. CENTRAL R (2020) Tait Shaun Walker; CORRESPONDENT, eastern Europe. Coronavirus: central Europe faces worse second wave after avoiding worst of first. The Guardian. ISSN 0261-3077.

2. FERJENCIK J (2000) Introduction to the methodology of psychological research: how to examine the human soul. Praha: Portal, ISBN 978-80-7367-815-9.

3. HENDL J (2004) Overview of statistical methods of data processing: analysis and meta-analysis of data. Praha: Poraál, ISBN 80-7178-820-1.

4. HROZENSKA M, DRZSIKOVA M (2016) Theoretical anchoring of clinical social work and social work in health care and their implications in practice according to the AngloSaxon model. In: Social work [online] 1. 11. 2016 [cit. 2021-08-08]. Available from http://socialniprace.cz/zpravy.php?oblast=1\& clanek=785.

5. KUZNIKOVA I (2011) Social work in healthcare. Praha: Grada, ISBN 978-80-2473676-1.

6. LACA S (2016) Social pedagogy versus social work, Praha: PVSPSS, ISBN 978-80-906237-
$0-5$.

7. MACKINOVA M, KOPINEC P (2019) Social worker in the medical equipment, Bratislava: University Komensky in Bratislava ISBN 978-80-223-4815-7.

8. MOJTOVA M (2008) Social work in healthcare. Bratislava: SAP, ISBN 978-80-8927145-0. 